\title{
GROWTH AND DETERMINATE SIZE IN INSECTS
}

\section{By Charles T. Brues.}

In common with nearly all metabolic activities, growth is essentially a determinate process, and size since it is the ultimate result or end product of growth, is inherently determinate also. To speak of the determinate size of an individual animal is therefore only to restate a self evident fact, and he who attempts to expound upon its truth may be accused of considerable naiveté. During the recent cycle of biological investigation much attention has been given to the phenomena of growth, especially by physiologists, geneticists and statistical biologists. These workers have defined in mathematical terms certain of the more evident features of growth both in individual organisms and in populations, but I believe that it remains for some one more deeply interested in another phase of biology, namely taxonomy, to consider size as in a sense a static phenomenon in spite of the fact that it is clearly a measure of growth. This is particularly appropriate in dealing with insects, since in them the growth process is ordinarily very rapid, ceasing abruptly and not gradually slowing down. Such observations are necessarily less precise than the data just mentioned, but they serve to demonstrate the existence of a deep-seated and stable genetic constitution which determines size and the growth process by which it is attained in individual animals. Size as we shall consider it, results from the interaction of a series of excitatory and inhibitory stimuli during the development of an individual whereby its growth follows quite closely a definite and predictable course, terminating when adult size is attained. Such termination is particularly definite in the case of insects where almost without exception the imaginal or reproductive stage marks sharply the attainment of final size and form. 
This determinate and definitive size involves certain gross characteristics, irrespective of the multiplicity of factors which have produced it, that are patent to any student of taxonomy. Those to which I shall refer to-day relate to comparative imaginal size in insects, although, since absolute size is directly dependent upon rate and time of growth, these cannot be eliminated completely from any discussion of size.

We usually speak of insects as small animals, but there exist great variations in size in practically every extensive taxonomic group. We find that some beetles, for example, are in bulk several million times as large as other beetles, if we compare the largest Scarabæoidea with certain minute Ptiliidæ. Many less striking differences appear in other orders and I have been tempted to draw upon an admittedly scattered knowledge of insects in general to illustrate certain size peculiarities in various groups.

Insects are by no means an exception among extensive groups of animals by reason of their great variation in size, as very similar or greater diversity may be pointed out in other classes of animals, as the Crustacea, fishes or mammals, or in the Phylum Mollusca, if we compare certain minute gastropods with giant squids. In all animals size shows a marked correlation with taxonomic groupings, $i$. e., size must be regarded as having an inherently stable genetic basis which is its primary determinant. Secondarily it is modified with reference to food or climate, but such modifications do not show any great constancy, regularity or extent. Thus in the tropics the size of certain types of insects is increased, for example, many scarabæoid beetles are represented there by species much larger than those in cooler regions, and the same is true in some other groups. On the other hand the reverse obtains among other types, although it must be admitted that tropical climates on the whole favor larger size in insects if we compare members of the same group and especially species in single families. Among marine invertebrates large size is very often associated with cold waters, but a reverse condition occurs in some groups. The largest living terrestrial mammals are tropical, yet in some families the species are decidedly larger in 
cold climates. Among reptiles the largest forms are very clearly those of the tropics. Without multiplying examples further it is evident that neither' warm nor cold climates can be regarded as constant stimuli to large size among animals in general. Thus certain types appear to wax larger in one to which they are usually said to be best adapted. The accuracy of such a conclusion is certainly open to question, as it is based on the dubious assumption that increased size is indicative of a more perfect adaptation to the environment.

I shall hope to be pardoned for introducing the foregoing long series of commonplace statements, but it appears necessary to have them in mind before going any further.

In general, the average size of insects has probably decreased during the history of the group on the earth, at least during its early history, but these changes have been very slight compared with the great increases in size that occurred, for example, very early in the history of the mammalia, in certain special groups of mammals, and among the mesozoic reptiles during their period of ascendency. Among these mammals and reptiles this great increase in size has consistently led to the extinction of the groups in which it occurred. Since some primitive types of living insects are of very small size, we may reasonably believe that such small forms were more abundant during the early history of insects than actual paleontological discoveries have yet been able to show. We know in some cases like that of the early giant dragon-flies that comparatively large size still persists as a general characteristic of recent Odonata. The same is true generally in other groups like the Blattariæ, Orthoptera, Mantodea and Corrodentia which tend to adhere rather closely to the size-range which prevailed among their ancient prototypes. Thus conservatism in size appears to be a characteristic of insect groups over long periods of time. The failure of any insects to attain a size comparable to that of certain giant Crustacea is usually attributed to their aërial habitat which renders their soft bodies highly susceptible to gravitational and traumatic deformation at the time of molting. This is certainly not the entire story, however, as there are no un- 
usually large aquatic insects, and the body-shape of large insects is not that which would lessen gravitational stresses. We must certainly admit that there is some good reason, probably dependent in great part upon the insect's respiratory and circulatory systems, which acts still more strongly to keep its body-size below certain limits. However, as the vast majority of insects do not tend to approach these limits, such factors are obviously not important ones in regulating size as between minute, small or moderate-sized forms. We may expect to find correlations between the size of the egg or its contained embryo and the size of the imaginal insect, and it would be totally unexpected if definite correlations were not to be found. It is surprising to note, however, that such a correlation is by no means universal. Many rather large insects, like meloid beetles, produce a large number of small or minute eggs, and a survey of such cases reveals quite universally some type of development which exposes the early stages to great vicissitudes of life. On the other hand some small or minute insects produce comparatively very large eggs or young, such as certain phorid flies and aphids, and the pupiparous Diptera. There are also very striking examples to be found among the parasitic tachinid flies where closely similar forms produce either many small, or a few large eggs, respectively, irrespective of the size of the parent flies. In all such cases differences in size at birth are not correlated with imaginal size, and represent highly adaptive modifications with reference to post-embryonic growth which have not in the least affected imaginal size.

Since the primary requirement for growth is food we may expect to find size in insects dependent at least to some degree upon abundance or type of food. Vegetarian diet furnishes a much more constant and plentiful source of food materials than that available for forms that depend upon animal foods, but larger amounts are necessary to supply equal energy. It is very evident in groups where both types of food habits occur that the vegetarian forms are more numerous in individuals, but do not develop to greater size. This is well illustrated by the very populous colonies of those ants which subsist on plant food in comparison with 
carnivorous species where the colony is consistently smaller. Here individual size does not respond to abundant food supply, but instead an increase in the number of individuals or in the size of the colony occurs. This condition appears to be repeated very generally in other, non-social, groups of insects, although increase in numbers is not so patent in the case of non-gregarious species. It must be said, however, that the bulkiest of all insects like the goliath beetles, hercules beetles, certain phasmids, saltatorial Orthoptera, giant silk-worms and the like are vegetarian, although the dragon-flies, tarantula-killer wasps and mantids of carniverous habits attain exceptionally large size. Also, the largest insects which, so far as we know, ever existed were predatory dragon-flies. It may be said as a rule that the smallest insects as well are vegetarian, saprophagous or microphagous although there are many minute entomophagous parasites. Predatory or carnivorous forms are neither abundantly represented among the smallest forms of insect life, nor are they conspicuously numerous among the largest.

Abnormalities in size among certain individuals may occur through a gross insufficiency of food during growth. Certain of the larger muscoid flies that develop in fermenting or decaying materials may vary considerably in size, frequently producing some greatly dwarfed individuals where their food supply has failed before larval growth was completed. Such specimens develop completely except for size. The partly grown larvæ of certain dermestid beetles may even decrease in size when starved and again grow to produce normally sized individuals when food is restored. Such abnormalities do not of course apply to our present discussion.

Certainly no generalizations concerning size in insects can be derived from the conflicting mass of details which present themselves when we attempt to correlate size with any of the foregoing trophic, developmental or environmental differences. Nevertheless, the size range in a great many taxonomic groups is very restricted; in others size varies widely, and occasionally giant forms appear singly or sporadically in groups otherwise very homogeneous in 
respect to size. Speaking in very general terms, several orders of insects include consistently small or minute species, for example the Protura, Collembola, Thysanoptera, Zoraptera, Mallophaga, Anoplura, Siphonaptera, Strepsiptera and Corrodentia, the last group being less appropriately cited as it includes a few moderate-sized species. Other orders include entirely or in great part large species, such as the Phasmatodea, Mantodea, Orthoptera, Blattariæ, Odonata and Megaloptera. It is noticeable in the latter series that small forms do occur here and there in practically all of the orders cited as there are a few very small Blattariæ and Orthoptera; moreover some Mantodea and Odonata are by no means large insects. In some orders size is extremely variable, for example in the Hemiptera, Neuroptera, Trichoptera, Lepidoptera, Diptera, Hymenoptera and Coleoptera. By far the majority of insects are included in these seven orders of which the last four are far and away the most extensive.

Several matters relating to size stand out very clearly from the rough approximations just outlined. Extensive groups composed of large species produce occasionally or sporadically small or dwarf types. Thus it appears that a reduction in size has been accomplished far more easily during the course of evolution in insects than has the reverse change whereby small types have given rise to large ones. The most extensive orders where speciation has been most active and where the appearance of diverse types has proceeded at a rapid rate, exhibit the widest range in size. It follows therefore that size and form show a strong tendency to remain constant or to vary together, not to be modified independently of one another. This is strong evidence that size has a strongly fixed genetic basis since it does not readily change, except in groups where morphological diversification and adaptation has been most extensive.

Even in these orders the fixity of size is well illustrated if we compare the subdivisions such as superfamilies or families. Among the Hymenoptera, for example, certain superfamilies show great constancy in size. The superfamilies Serphoidea, Chalcidoidea, and Cynipoidea include only small or minute species, with really only a single com- 
paratively "giant" generic type (Pelecinus, Leptofœnus and Ibalia, respectively) in each superfamily. This is true notwithstanding the fact that certain of the minute parasitic forms have developed the most unexpected method of development, known as germinogony, whereby a single egg produces enough larvæ to consume a large caterpillar. Here numbers replace size in exploiting the trophic field. On the other hand in the same order Hymenoptera other superfamilies do not show such constant size. The Tenthredinoidea, Ichneumonoidea, Vespoidea and Formicoidea include moderate-sized species with numerous small and scattered large types, showing that a wide variation in size in this extensive order is characteristic only of certain groups. The largest known Hymenoptera are Jurassic Siricoidea, a superfamily whose living representatives are still characteristically large insects with a few small, derived types.

Another very extensive order, the Lepidoptera, show more or less similar conditions with reference to size. This group was at one time rather crudely divided into "Microlepidoptera" and "Macrolepidoptera." The former group is really composed almost entirely of one superfamily, the Tineoidea with a slight admixture of more primitive forms (Micropterygoidea) that are really quite closely similar to certain much larger ones (Hepialoidea) near which they are now placed. The more rational taxonomic grouping of these primitive types into two superfamilies corresponds closely to the size of the included types.

With these facts in mind we must discard at once any supposition that relates body size in insects to fortuitous circumstances or to adaptations readily acquired in relation to a changing or specialized type of environment. Size appears as a highly stable character, deeply imbedded in the genetic constitution of at least most groups of insects. 

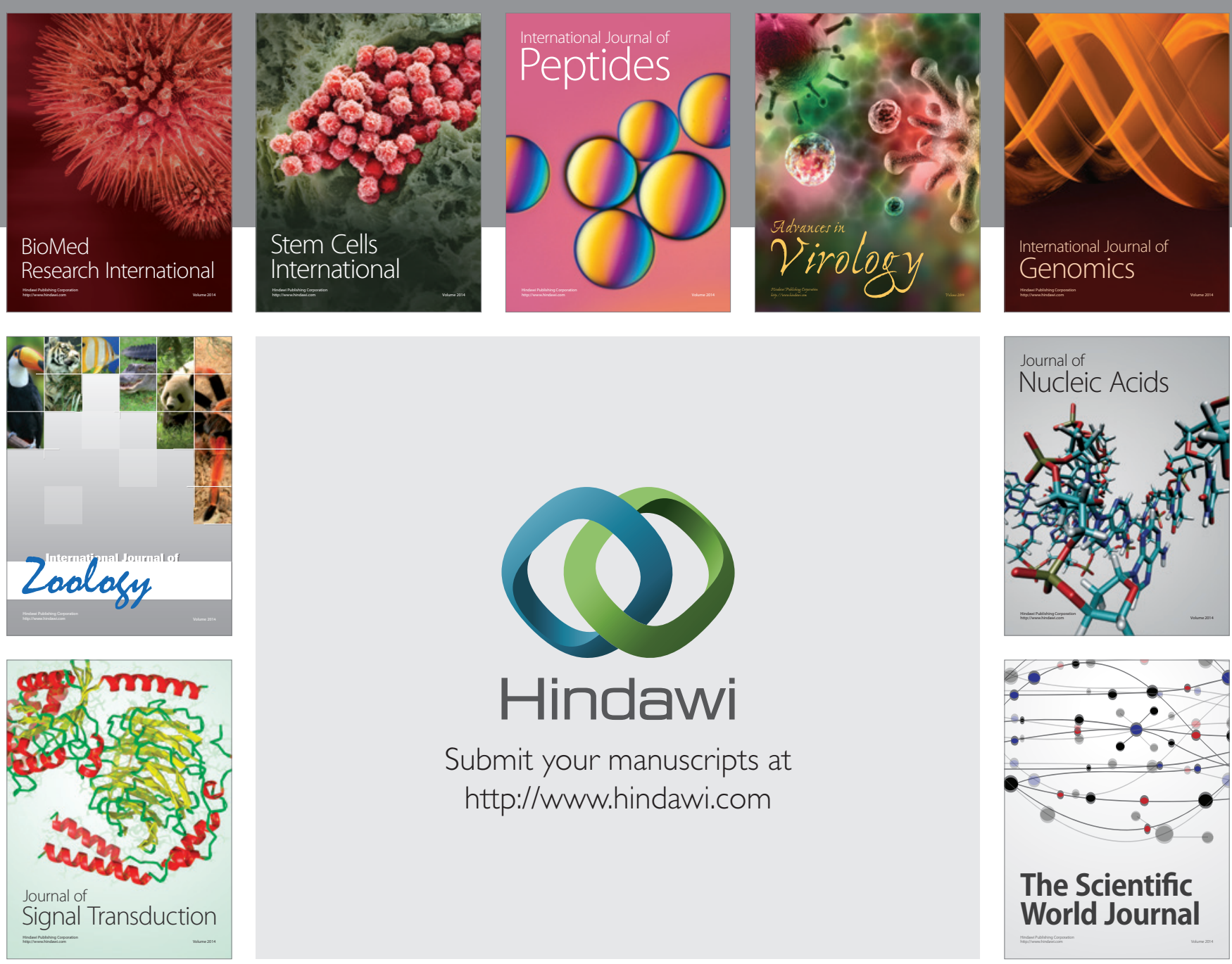

Submit your manuscripts at

http://www.hindawi.com
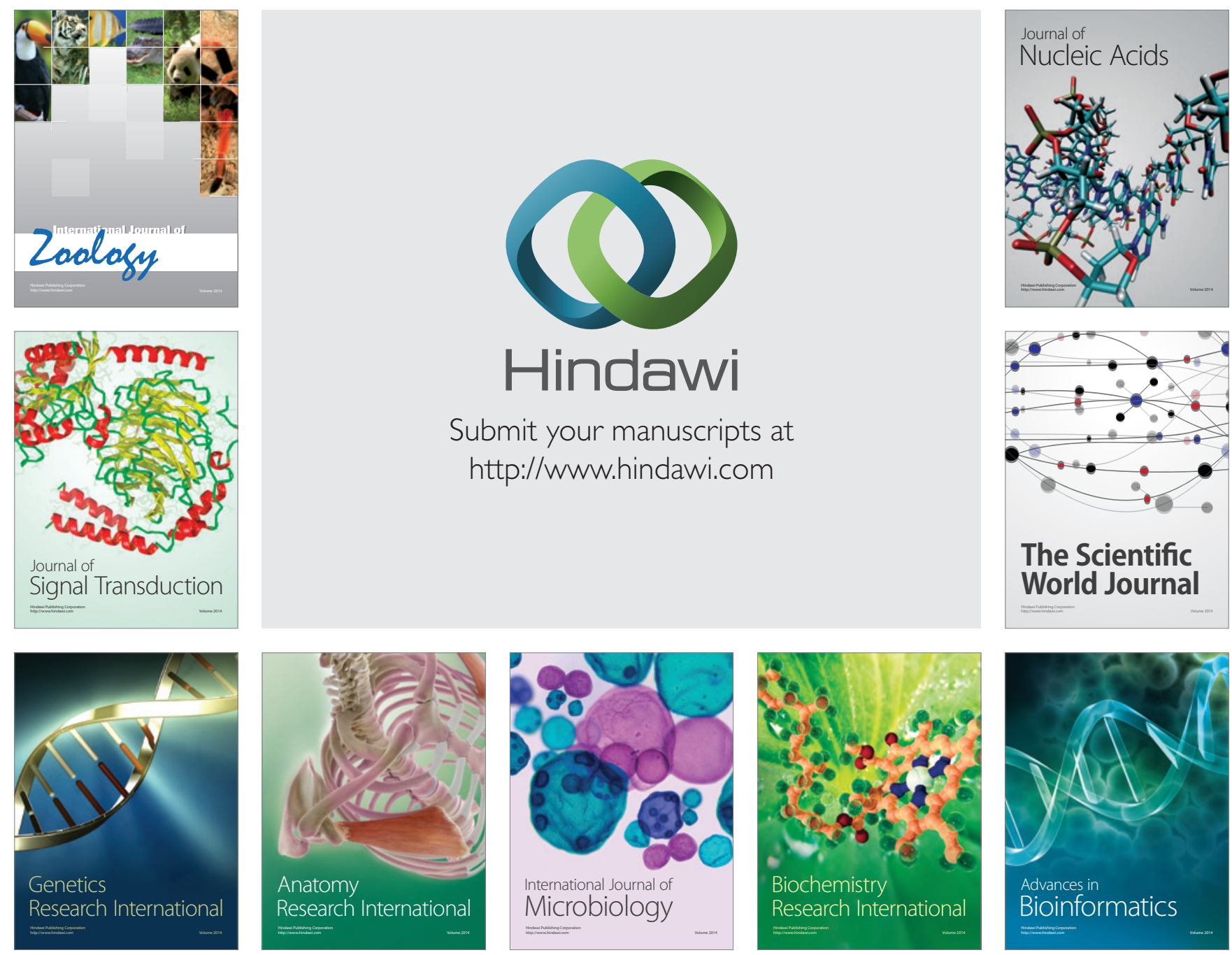

The Scientific World Journal
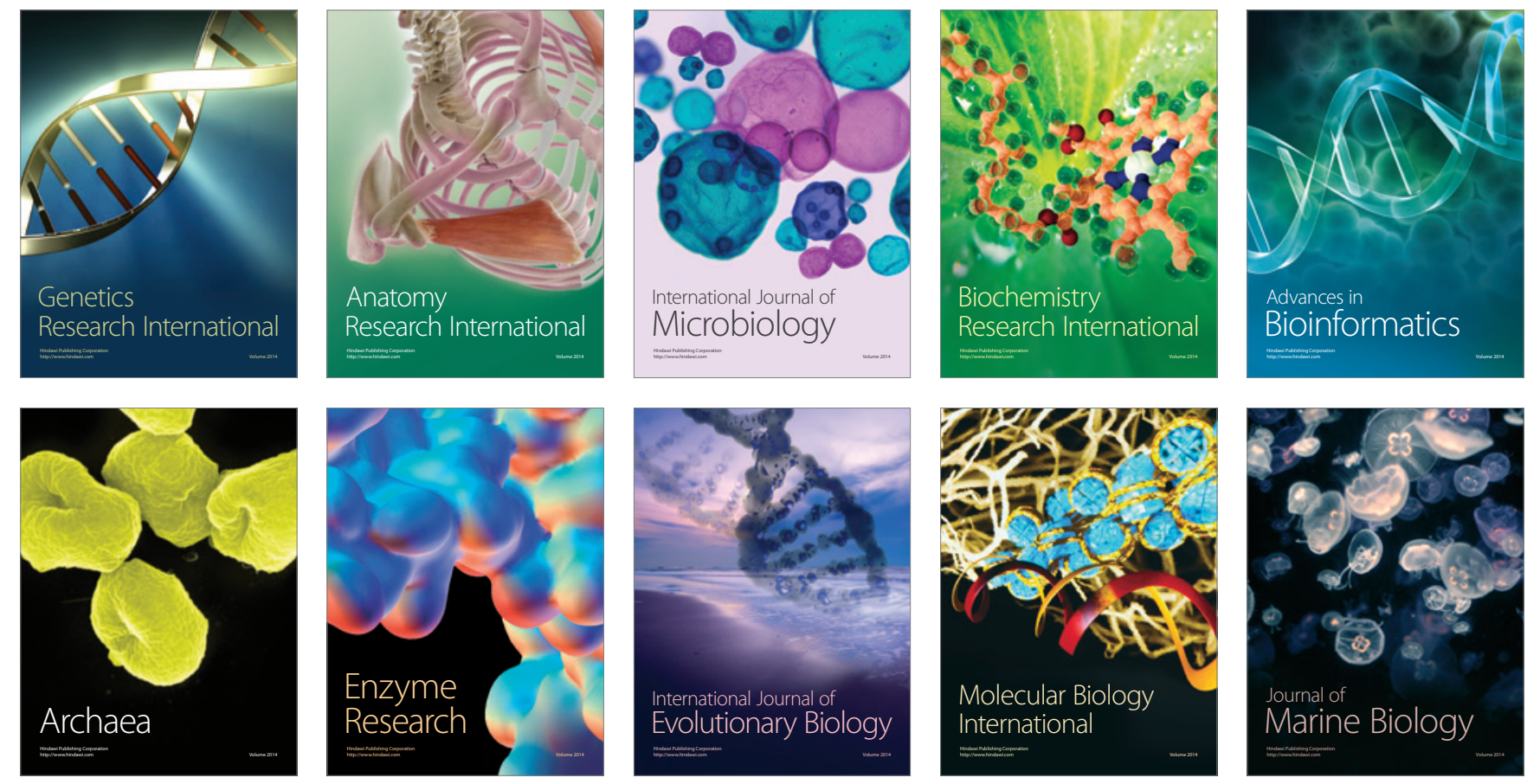